\title{
The formation and properties of polypyrrole doped with an immobile antibiotic
}

\author{
Emer Moloney ${ }^{1} \cdot$ Carmel B. Breslin ${ }^{1}$ (i)
}

Received: 8 March 2019 / Revised: 30 April 2019 / Accepted: 3 May 2019 / Published online: 20 May 2019

(C) Springer-Verlag GmbH Germany, part of Springer Nature 2019

\begin{abstract}
Oxacillin, a semisynthetic penicillinase-resistant penicillin, was incorporated as a dopant within polypyrrole. The oxacillin-doped polymer was deposited at gold, platinum and the biocompatible substrate, titanium. A doping level of 0.12 was obtained during the early stages of polymer formation. Smooth polymer films were deposited, but more structure was observed in the cross sections of the polymer. This was attributed to a reduction in the concentration of the anionic oxacillin as the interfacial $\mathrm{pH}$ decreased due to the electropolymerisation reaction, shifting the equilibrium in favour of the undissociated oxacillin, HOx. Although HOx has poor solubility and may precipitate at the polymer solution interface during formation of the polymer, there was no evidence of any reduction in the conducting properties of the polymer. High charging capacitance values of 12 to $15 \mathrm{mF} \mathrm{cm}^{-2}$ were estimated for the oxidised polymer. These conducting properties were attributed to a slow rate of electropolymerisation that prevented significant acidification at the electrode interface, preventing the build-up of HOx. The oxacillin-doped polypyrrole showed cation exchange properties. Oxacillin was maintained within the polymer, as the polymer was cycled between its oxidised and reduced states to give an immobilised antibiotic with very little oxacillin detected in the solution phase. The application of a layer of chitosan gave rise to a slight reduction in the charging capacitance of PPyOx. However, improved adhesion was observed for the reduced PPyOx with the application of the chitosan layer.
\end{abstract}

Keywords Polypyrrole $\cdot$ Antibiotic $\cdot$ Oxacillin $\cdot$ Electropolymerisation $\cdot$ Chitosan

\section{Introduction}

In recent years, there has been considerable interest in conducting polymers, and in particular polypyrrole, in biomedical applications [1]. Polypyrrole is easily formed and fabricated using electropolymerisation with a suitable dopant, or by chemical polymerisation where a dopant and an oxidising agent are employed. It can also be formed with different morphologies, ranging from the typical porous cauliflower films to various nanostructured assemblies [2]. In terms of biomedical applications, it has been shown that polypyrrole can support cell adhesion and growth of a number of different cell types, including endothelial cells, neurons and support cells, and it can also stimulate skeletal myoblasts and cardiac myocytes [3,4]. There is also interest in using

Carmel B. Breslin

Carmel.Breslin@mu.ie

1 Department of Chemistry, Maynooth University, Maynooth, Co. Kildare, Ireland polypyrrole as implant coatings and in the design and manufacture of neural prosthetics that are capable of integrating with tissues. It has been shown that polypyrrole can stimulate damaged neural tissues to repair and reconnect [5]. As the applications of polypyrrole extend further to wearable electronic textiles and implant coatings, infection mitigation becomes more important $[6,7]$. Due to the antibacterial activity of silver ions and silver particles, it is no surprise that silver nanoparticles or ions have been loaded onto polypyrrole to give antibacterial coatings. Composites comprising conducting polymers with silver are easily produced on oxidation of the respective monomers in the presence of silver salts. In addition, silver ions are readily reduced to the metal in the presence of both polypyrrole and polyaniline $[8,9]$. However, leaching of the nanoparticles and silver ions from polypyrrole to the environment is a concern, and this compromises their biomedical applications.

Another strategy is to incorporate antibiotic molecules as dopants within the polypyrrole film. A number of drug molecules, including glutamate, adenosine 5'-triphosphate (ATP), salicylate, dexamethasone, chlorpromazine and dopamine, 
have been successfully incorporated into polypyrrole and subsequently released using electrical stimulation [10-16]. The drug molecules, as anions, are added to the electropolymerisation solution, and during electropolymerisation, they are doped within the growing polymer. Drug-loaded polymers have been formed using a constant applied current density [17], cyclic voltammetry [18] and at a constant applied potential [19]. The anionic drugs are retained as dopants while the polymer films are maintained in an oxidised state, but in order to maintain charge neutrality, they are expelled from the polymer on reduction of the film. The incorporation and release of cationic drugs or molecules, such as dopamine [10], have also been achieved.

In relation to the incorporation of large molecules as dopants within the polypyrrole matrix, the ion exchange properties of polypyrrole become important, and these depend on the nature of the doping anions, with the size and valence of anions being especially significant [20-23]. During redox cycling, charge neutrality is maintained with the transfer of small doping anions, such as chloride anions, between the electrolyte solution and the polymer matrix. These anions are released on reduction when the positively charged polymer backbone becomes neutral. On the other hand, the release of large charged dopants is considerably more difficult, and the polymer becomes predominantly a cationic exchanger, with the influx of cations on reduction of the polymer [20-23]. Furthermore, many of the large molecules have weak acid functional groups, and when dissolved in solution, an equilibrium is established between the neutral molecule and the anion formed on dissociation. During the electropolymerisation of pyrrole, the solution adjacent to the electrode surface becomes acidified and the interfacial $\mathrm{pH}$ is reduced. As a consequence, the equilibrium is shifted to favour the neutral undissociated molecule, and this will result in a lower concentration of the anionic dopant, which is required for electropolymerisation. If the neutral molecule has a low solubility, which is generally the case with large organic-like molecules, then precipitation of the molecule occurs to limit or prevent electropolymerisation. This was shown by Ryan et al. [24] for the sodium salts of diclofenac and valproic acid, where the formation of the insoluble neutral molecule prevented the formation of polypyrrole doped with valproate and gave rise to the deposition of crystals of diclofenac, limiting the formation of the polymer doped with diclofenac.

In this paper, an antibiotic, oxacillin (5 methyl-3-phenyl-4isoxazolyl penicillin sodium), was incorporated as a dopant into polypyrrole, and the conducting polymer was formed at both platinum and titanium in an attempt to provide an immobilised antibiotic. Oxacillin $(\mathrm{Ox})$, which is derived from 6-aminopenicillanic acid, is a semisynthetic penicillinaseresistant penicillin. It has low toxicity for the host, but it is effective against most gram-positive bacteria in humans and animals, including pathogens (streptococci, staphylococci and pneumococci), clostridia, some gram-negative gonococci, some spirochetes (Treponema pallidum and T. pertenue) and some fungi $[25,26]$. It is used in its sodium salt for parenteral administration. Therefore, the sodium salt of oxacillin is a potential dopant, providing an anionic species that can be incorporated within the polymer film, while its large size may inhibit or minimise its release to give an immobilised antibiotic.

\section{Experimental method}

The chemicals used throughout this study were purchased from Sigma-Aldrich (Analar grade reagents). Pyrrole was vacuum distilled and stored in the dark at $-20{ }^{\circ} \mathrm{C}$ prior to use. A standard three-electrode cell was used for all experiments. A high-surface-area platinum wire served as the counter electrode, and a saturated calomel electrode (SCE) was used as the reference electrode. Platinum, gold and titanium disc electrodes (99.99\% purity) with a surface area of $0.126 \mathrm{~cm}^{2}$ were employed as the working electrode. These electrodes were fabricated by embedding the metal rods in a Teflon holder, which was filled with epoxy resin, and a copper wire was threaded into the base of the metal sample for electrical contact. The exposed surface was polished to a mirror finish using successively smaller sizes of diamond paste to a final size of $1 \mu \mathrm{m}$ on a microcloth (Buehler). The surface of the electrode was then rinsed with distilled water, cleaned in an ultrasonic bath to remove any polishing residues and finally dried in a stream of air.

Cyclic voltammetry and potentiostatic current-time plots were carried out using a Solartron (Model SI 1287) potentiostat. The quartz crystal microbalance (EQCM) experiments were carried out on a CHi440 EQCM system. The polymers were deposited onto polished titanium quartz crystal electrodes (Cambria Scientific) with an exposed surface area of $0.203 \mathrm{~cm}^{2}$. The electrochemical cell consisted of a specially made Teflon holder in which the crystal was placed between two o-rings, a platinum wire counter and a custom-made $\mathrm{Ag} \mid \mathrm{AgCl}$ reference electrode. The Sauerbrey equation (Eq. 1 [27]) was used to convert the oscillation frequency to the mass at the crystal. In this equation, $\Delta f$ represents the observed frequency shift, $\Delta m$ corresponds to the mass change, $\mu_{\mathrm{q}}$ and $\rho_{\mathrm{q}}$ are the shear stress and density of quartz, respectively, $f_{\mathrm{o}}$ is the resonant frequency, and $C_{\mathrm{f}}$ is the sensitivity of the crystal, which was found experimentally to be $7.9897 \times$ $10^{8} \mathrm{~Hz} \mathrm{~cm}^{2} \mathrm{~g}^{-1}$. Thin polymer films were deposited to minimise viscoelastic effects, as this analysis is only valid for thin, uniform and rigid films on the crystal. 
$\Delta m=-\frac{A \sqrt{\left(\rho_{\mathrm{q}} \mu_{\mathrm{q}}\right)}}{2 f_{\mathrm{o}}^{2}} \Delta f=\frac{1}{C_{\mathrm{f}}} \Delta f$

Electrochemical impedance spectroscopy was carried out using a Solartron (Model SI 1287) potentiostat coupled to a Solartron frequency response analyser (Model 1255). The frequency was varied from $65 \mathrm{kHz}$ to $8 \mathrm{MHz}$ using a potential perturbation of $10 \mathrm{mV}$. All data were recorded following a 120-min polarisation period to ensure steady-state conditions. The data were fitted to equivalent circuits, where the errors in the fitted element were less than $2.8 \%$. The surface morphology of the polymer samples was obtained using a Hitachi scanning electron microscope. The samples were sputter coated with gold using an Emitech K550x gold sputter coater prior to analysis.

The PPyOx was deposited from a solution containing $0.2 \mathrm{M}$ pyrrole and $0.02 \mathrm{M}$ oxacillin at a $\mathrm{pH}$ of 6.3 , while all electrochemical characterisation studies were carried out in a saline phosphate-buffered solution (PBS) $(0.15 \mathrm{M} \mathrm{NaCl}$, $0.04 \mathrm{M} \mathrm{NaH}_{2} \mathrm{PO}_{4}$ and $0.04 \mathrm{M} \mathrm{NaOH} ; \mathrm{pH}$ 7.4). A chitosanmodified PPyOx film was formed by drop casting a chitosan solution onto the surface of the polymer. This solution was prepared by dissolving $0.125 \mathrm{~g}$ chitosan in $25 \mathrm{~cm}^{3}$ of $2.0 \mathrm{M}$ ethanoic acid to give a $0.5 \% \mathrm{w} / \mathrm{v}$ composition. The solution was stirred for $180 \mathrm{~min}$ and then filtered. The chitosan film was prepared by drop casting $10 \mu \mathrm{L}$ of this solution onto the surface of PPyOx. The chitosan-loaded film was then dried under an infrared lamp for $10 \mathrm{~min}$.

The release of oxacillin from the polypyrrole matrix was monitored using UV-visible spectroscopy (Cary 50 UVvisible spectrometer) by measuring the maximum absorbance at $205 \mathrm{~nm}$. The UV spectrum of oxacillin in PBS was recorded over a 24 -h period to validate the quality of detection. A broad wave between 220 and $250 \mathrm{~nm}$ became slightly more pronounced, but the peak at $205 \mathrm{~nm}$ remained constant. A linear calibration curve was obtained at $205 \mathrm{~nm}$, and this was used to give the concentration of oxacillin released from the PPyOx films. Once formed, the polymer was thoroughly washed in water and then immersed in distilled water for a 3 -h period to remove any oxacillin trapped and not doped within the porous polymer matrix. The solution was stirred during this period and the cell was wrapped in aluminium foil to exclude light. All release studies were carried out in the PBS solution and repeated three times, and the standard error was calculated.

\section{Results and discussion}

The chemical structure of oxacillin sodium (5 methyl-3phenyl-4-isoxazolyl penicillin sodium), which is classified as a beta-lactam antibiotic in the penicillin class, is shown as the sodium salt, in Fig. 1a. The acyl side chain sterically inhibits the opening of the $\beta$-lactam ring. Although $\mathrm{Ox}^{-}$is large, with steric hindrance, its dissociation as a salt with good solubility in water makes it a suitable anionic dopant for polypyrrole. However, an equilibrium between the oxacillin anion, $\mathrm{Ox}^{-}$, and its corresponding neutral acid form, HOx, exists in solution, as shown in Eq. 2. Using the well-known HendersonHasselbalch equation and the pKa of oxacillin, which is 2.7, the percentage $(\%)$ of oxacillin ions in solution can be estimated as a function of pH, as illustrated in Eq. 3.

$$
\begin{aligned}
& \mathrm{HOx} \leftrightharpoons \mathrm{H}^{+}+\mathrm{Ox}^{-} \\
& \%\left[\mathrm{Ox}^{-}\right]=\frac{100}{1+10^{\left(\mathrm{pK}_{\mathrm{a}}-\mathrm{pH}\right)}}
\end{aligned}
$$

The corresponding plot is shown in Fig. 1b, where it is evident that the concentration of the anionic oxacillin begins to decrease rapidly as the $\mathrm{pH}$ is reduced to values in the vicinity of 3.0. It is well known that protons are released during the electropolymerisation reaction, and this decrease in the interfacial $\mathrm{pH}$ will alter the anionic oxacillin concentration. The degree of acidification will depend on the rate of electropolymerisation. Interfacial $\mathrm{pH}$ values between 2.0 and 3.0 have been reported during the electropolymerisation of pyrrole in the presence of perchlorate and chloride anions [28]. Therefore, in order to maintain a sufficient concentration of oxacillin at the electrode surface and to avoid the formation of HOx, which has poor solubility, relatively low rates of electropolymerisation were employed.

\section{Formation of PPyOx}

The polypyrrole oxacillin films, PPyOx, were deposited from an electropolymerisation solution containing $0.2 \mathrm{M}$ pyrrole and $0.02 \mathrm{M}$ oxacillin. No additional ions were added. A constant potential of $0.80 \mathrm{~V}$ vs SCE was used to achieve electropolymerisation at a rate where significant acidification is prevented. A typical current-time plot is shown in Fig. 2, where the time required to achieve a charge of $0.25 \mathrm{C}$ is approximately $8 \mathrm{~min}$. On application of the potential, the charging current decays rapidly and is then followed by a slower rise, at about 5 to $10 \mathrm{~s}$, as the polypyrrole film begins to nucleate and deposit at the surface. At longer times, greater than $50 \mathrm{~s}$, the current reaches a steady state. There is no evidence of any decay in the steady-state current, indicating that the deposition of insoluble HOx is largely prevented. Figure 2 shows comparative current-time curves and charge-time plots for the nucleation of $\mathrm{PPyCl}$ and PPyOx. There is a linear charge-time plot for the formation of the $\mathrm{PPyCl}$ film, and the charge-time plot is linear at longer electropolymerisation times, from 50 to $500 \mathrm{~s}$, for the PPyOx film. The rate of electropolymerisation is significantly higher for the $\mathrm{PPyCl}$ system. This may be due to the size of the anions $\mathrm{Cl}^{-}$ 
Fig. 1 a Chemical structure of oxacillin sodium salt. $\mathbf{b}$ Percentage $(\%)$ of oxacillin anions in solution as a function of $\mathrm{pH}$ (a)

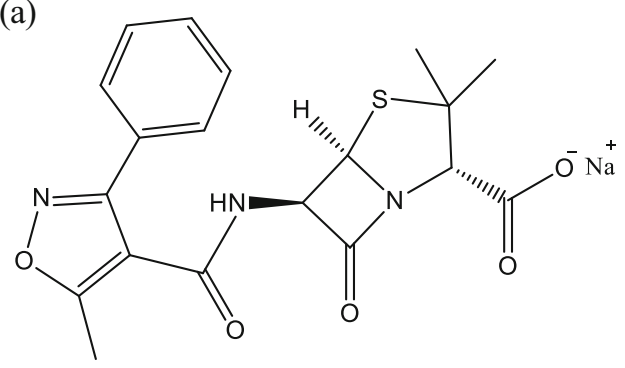

(b)

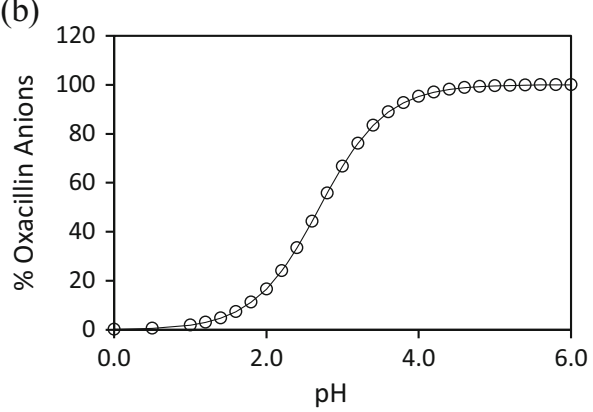

(35 $\mathrm{g} \mathrm{mol}^{-1}$ ) and $\mathrm{Ox}^{-}\left(400 \mathrm{~g} \mathrm{~mol}^{-1}\right)$ and the added steric hindrance in the oxacillin dopant. This makes it difficult for the dopant to align its anionic carboxylic group adjacent to the positive charge on the polypyrrole backbone. Another possibility is that the higher charge density on the oxygen atoms of the oxacillin causes a stronger interaction with the pyrrole oligomer [29], altering the configuration of the oligomer. Nevertheless, these lower rates of electropolymerisation limit the degree of acidification and the precipitation of HOx.

The deposition of PPyOx on different substrates was also studied at $0.80 \mathrm{~V}$ vs SCE from a solution containing $0.2 \mathrm{M}$ pyrrole and $0.02 \mathrm{M}$ oxacillin. Figure 3 shows the current-time and charge-time curves for PPyOx on different metallic substrates. It is evident that the $\mathrm{PPyOx}$ grows at different rates on the three substrates. During the early stages of deposition, the rate of electropolymerisation is higher at platinum. An initial nucleation or induction period must elapse before bulk polymer deposition occurs, and while this is evident at all three electrodes, it is somewhat longer for the titanium electrode. However, at longer electropolymerisation periods, more efficient deposition is achieved at titanium. The average rate of growth, obtained using the linear portions of the charge-time plots, was computed as $0.39 \mathrm{mC} \mathrm{s}^{-1}$ for platinum, $0.30 \mathrm{mC} \mathrm{s}^{-1}$ for the gold electrode and $0.55 \mathrm{mC} \mathrm{s}^{-1}$ on a titanium electrode. Strongly adherent polymer films were formed at the titanium electrode. In contrast, the formation of $\mathrm{PPyCl}$ at the titanium electrode was considerably more difficult, and only patches of the deposited polymer that were poorly adherent to the substrate were obtained. It is well known that poorly adherent polypyrrole films are formed on titanium and its alloys due to the competing electropolymerisation and oxidation of the substrate to form metal oxides [30]. The latter process gives
Fig. 2 a Current-time plots for the growth of PPyOx and $\mathbf{b}$ current-time plots and $\mathbf{c}$ chargetime plots for the formation of $\mathrm{PPyCl}$ (dotted line) and PPyOx (solid line) at $0.80 \mathrm{~V}$ vs SCE
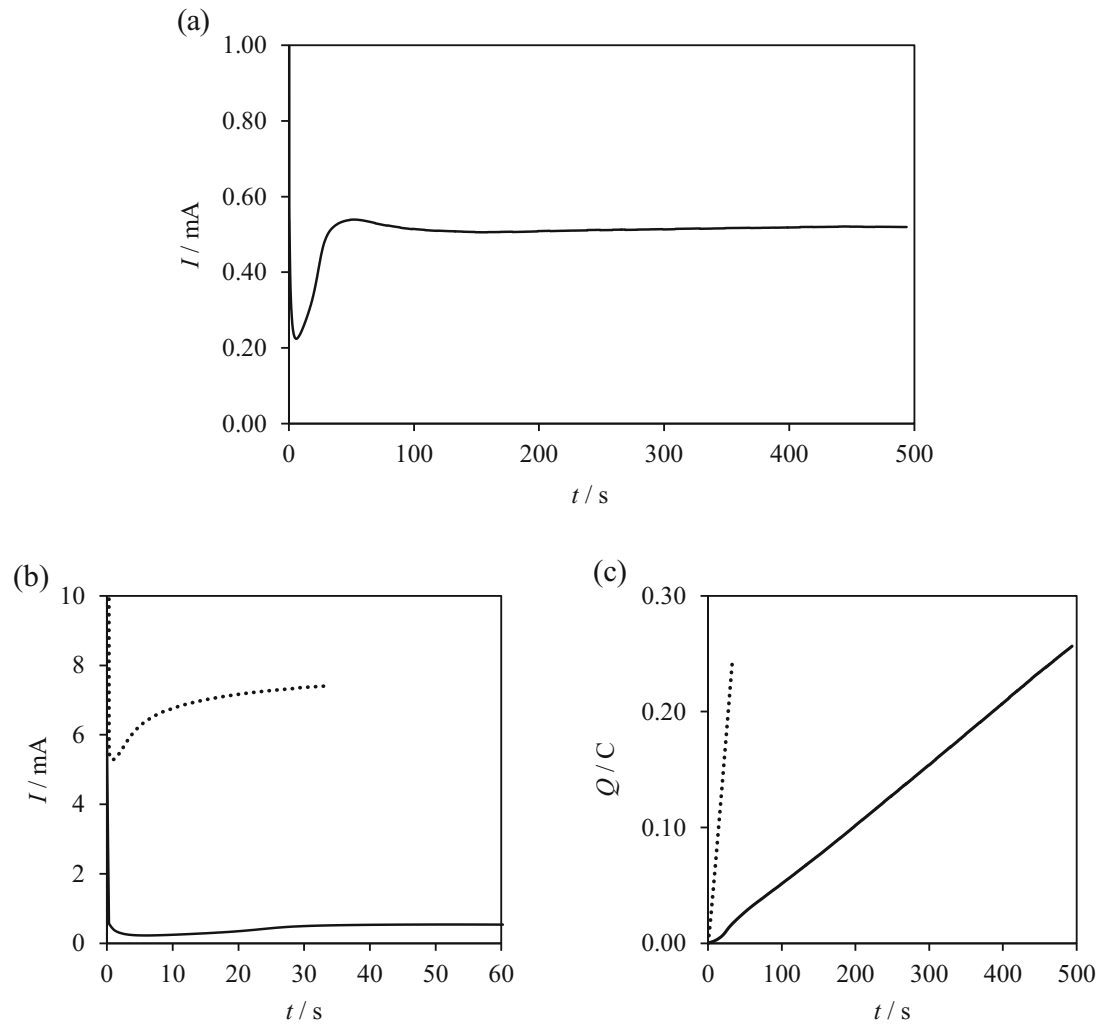
Fig. 3 a Current-time and $\mathbf{b}$ charge-time plots for the formation of PPyOx on Pt (solid line), $\mathrm{Au}$ (dashed line) and $\mathrm{Ti}$ (dotted line) electrodes at $0.80 \mathrm{~V}$ vs SCE

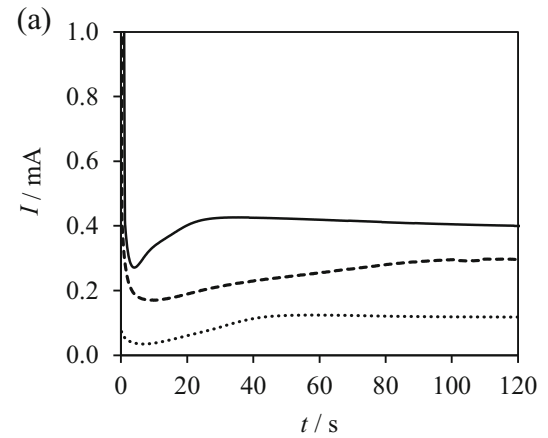

rise to passivation of the electrode, and this not only inhibits the electropolymerisation process but also leads to poor adhesion of the polymer to the substrate. The more favourable electropolymerisation at titanium in the presence of oxacillin may be connected to the adsorption of oxacillin at the titanium electrode. The influence of oxacillin on the electrochemistry of platinum in PBS is shown in Fig. 4, where it is clear that adsorption of oxacillin occurs giving rise to a significant reduction in the peaks associated with hydrogen ion adsorption and there is no evidence of any oxides formed in the presence of oxacillin. While this adsorption may initially inhibit the electropolymerisation step, it will also reduce the rate of oxidation of the metal.

Quartz crystal microbalance (EQCM) measurements were performed and analysed to obtain information on the doping level of the deposited PPyOx film. In these studies, the PPyOx was grown on a Ti EQCM crystal by applying a constant potential of $0.80 \mathrm{~V}$ vs $\mathrm{Ag} \mid \mathrm{AgCl}$. The frequency-charge and mass-charge plots for PPyOx are shown in Fig. 5a, b, respectively. A decrease in frequency is related to an increase in mass according to the Sauerbrey relationship (Eq. 1). There is a linear increase in mass with charge once the charge exceeds $5.0 \mathrm{mC} \mathrm{cm}^{-2}$ (approximately $17 \mathrm{~s}$ ). Good linearity was obtained after the elapse of the initial $17 \mathrm{~s}$. The doping level, $p$, of the oxacillin was estimated as 0.12 using Eq. 4 where $M_{\mathrm{m}}$ and

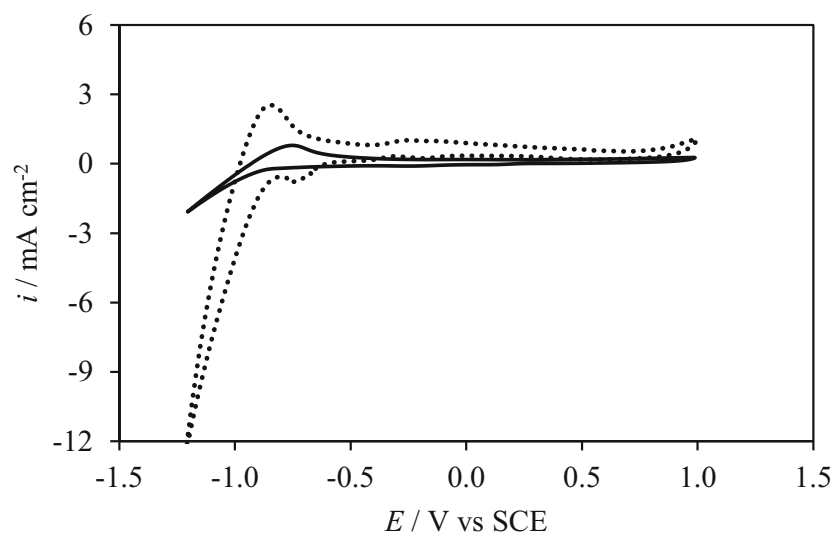

Fig. 4 Cyclic voltammograms recorded for platinum cycled at $50 \mathrm{mV} \mathrm{s}^{-1}$ in PBS in the absence (dotted line) and presence (solid line) of $0.02 \mathrm{M}$ oxacillin
$M_{\mathrm{A}}$ are the formula weights of the pyrrole monomer and oxacillin anion. However, a higher doping level may exist in the bulk polymer. As shown in Figs. 2 and 3, there is an induction or nucleation period where inefficient deposition of the polymer takes place. Therefore, this doping level applies only to the initial deposition of the polymer film.

$R=\frac{m}{Q}=\frac{M_{\mathrm{m}}+p M_{\mathrm{A}}}{(n+p) F}$

Doping levels for polypyrrole have been reported to range from 0.2 to 0.5 dopant species per pyrrole unit [31, 32]. For simple dopant anions such as $\mathrm{Cl}^{-}$, the value of $p$ is approximately 0.33 , i.e., a $1: 3$ doping ratio. The $p$ value of 0.12 corresponds to a 1:8 doping ratio, which is lower than that observed for doping with chloride anions, and this can be explained by the much larger size of oxacillin. However, this value is in good agreement with the analysis reported by Song et al. [33] where dopant ratios ranging from 1:2.5 to $1: 15$ were obtained for polypyrrole doped with dodecylbenzenesulfonic acid.

\section{Surface morphology}

A typical SEM micrograph of PPyOx formed at $0.80 \mathrm{~V}$ vs $\mathrm{SCE}$ is shown in Fig. 6a while the cross section of PPyOx deposited to a charge of $0.40 \mathrm{C}$ is presented in Fig. 6b. It is evident from Fig. 6a that the surface morphology is very different to the usual cauliflower morphology reported for polypyrrole, which is shown in the inset for a $\mathrm{PPyCl}$ film formed at $0.80 \mathrm{~V}$ vs SCE. Instead, the surface of the PPyOx film is smooth, with little visible contrast; however, there is some structure evident within the cross section (Fig. 6b). EDX analysis was carried out to verify the presence of the oxacillin dopant. The EDX spectrum (not presented) showed the presence of carbon at $0.3 \mathrm{keV}$, sulphur at $2.45 \mathrm{keV}$ and oxygen at $0.52 \mathrm{keV}$, indicating the incorporation of $\mathrm{Ox}^{-}$during the formation of the polypyrrole film.

The absence of the usual cauliflower structure shows that the incorporation of oxacillin or the presence of oxacillin during the electropolymerisation process 
Fig. 5 Frequency-charge and mass-charge plots for the electropolymerisation of pyrrole to generate PPyOx to a charge density of $75 \mathrm{mC} \mathrm{cm}^{-2}$ on a Ti EQCM crystal recorded by EQCM measurements (Linear plot (dashed line) and experimental data (solid line))

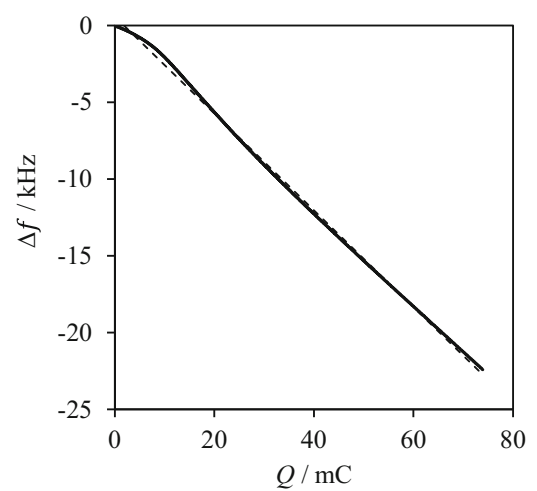

modifies the surface morphology. More compact and smooth polypyrrole films have been reported when pyrrole is electropolymerised in the presence of ionic liquids $[34,35]$. However, no mechanism has been proposed to account for this morphology. It is also apparent from Fig. 6a that some structures ranging in size from 4 to $7 \mu \mathrm{m}$ are present on the polymer surface. These structures and the smooth polymer films seem to be connected to variations in the oxacillin
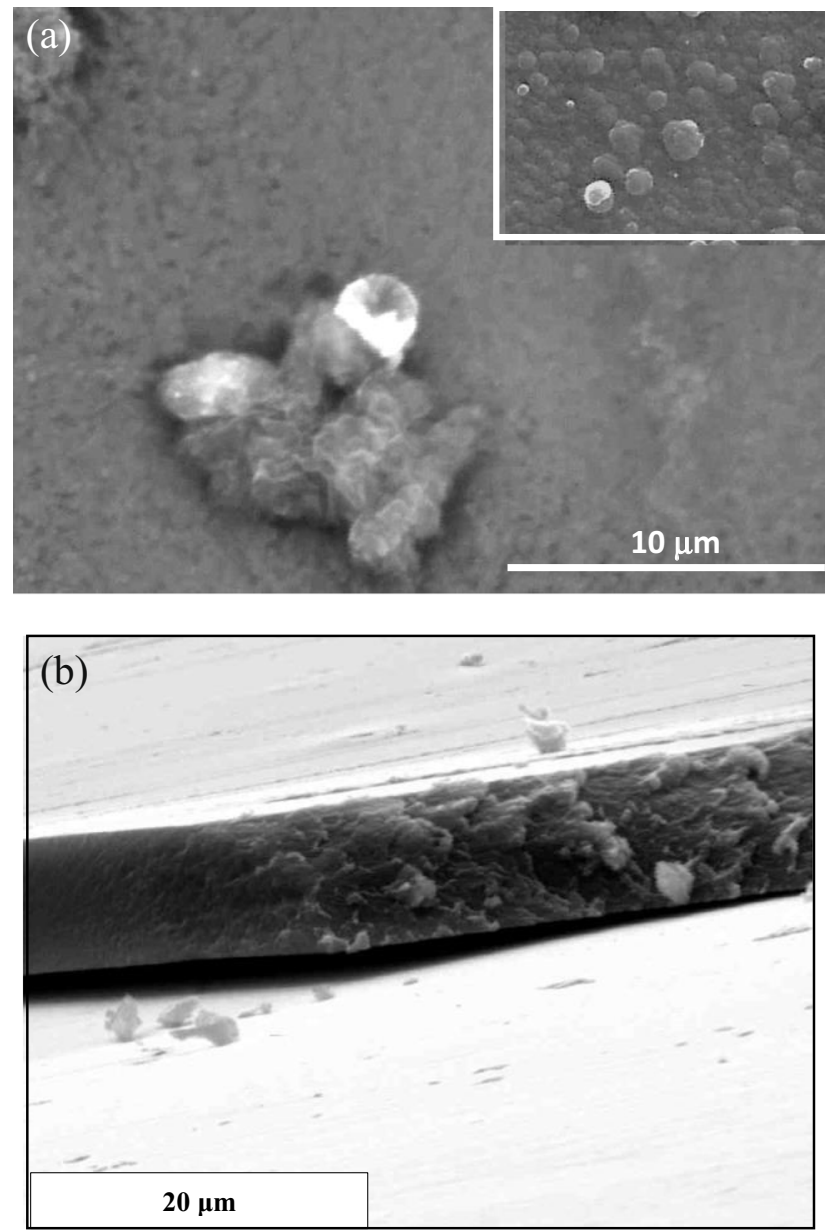

Fig. 6 a SEM micrograph of PPyOx formed at $0.80 \mathrm{~V}$ vs SCE. b Cross section of PPyOx grown to a charge of $0.40 \mathrm{C}$ concentration as the electropolymerisation proceeds to generate an acidified solution. As acidification begins, some of the oxacillin anions are removed and converted to HOx (Eq. 1 and Fig. 1b). This will reduce the rate of electropolymerisation and the number of polypyrrole nodules formed at the surface, which are connected to the typical cauliflower-like morphology. Furthermore, HOx has a much lower solubility in water, and insoluble HOx may precipitate at the surface, further reducing the rate of polymer formation and altering the surface morphology. Indeed, the structures on the surface of the polymer showed a higher count for sulphur compared with the bulk smooth polymer on analysing the surface using EDX analyses. This suggests that the structures may be connected to the precipitation of insoluble HOx. Nevertheless, it is clear that PPyOx is readily formed, as illustrated in Figs. 2 and 3, and this is possibly connected to the relatively low rate of electropolymerisation that prevents significant acidification and limits the formation of the insoluble $\mathrm{HOx}$ at the surface.

The cross sections were used to estimate the film thickness as $1.50 \pm 0.15 \mu \mathrm{m}$ for PPyOx deposited to $0.25 \mathrm{C}$. The film thickness of PPyCl grown to the same charge was measured as $0.5 \mu \mathrm{m}$. The significantly higher film thickness obtained with the PPyOx film is consistent with the higher molecular weight of oxacillin. Faraday's law (Eq. 5) was also employed to estimate the thickness, where $M$ is the molar mass of pyrrole, $q$ is the charge, $A$ is the surface area of the electrode, $z$ is the number of electrons transferred, $F$ is the Faraday constant, and $\rho$ is the density taken as $1.5 \mathrm{~g} \mathrm{~cm}^{-3}$. In this case, the film thickness of both PPyOx and PPyCl was estimated as $0.5 \mu \mathrm{m}$, giving good agreement with the values measured for $\mathrm{PPyCl}$ but illustrating a significant difference between the measured and calculated values of PPyOx, showing that Eq. 5 is not always appropriate for larger dopants.

$x=\frac{q M}{\rho A z F}$ 


\section{Conducting and cation exchange properties}

The conducting properties of PPyOx were characterised using cyclic voltammetry and electrochemical impedance spectroscopy. For the cyclic voltammetry experiments, the polymers were formed at $0.80 \mathrm{~V}$ vs SCE to a charge of $0.25 \mathrm{C}$ and then cycled in a PBS solution ( $\mathrm{pH} 7.4)$ where the potential was swept from 0.35 to $-0.95 \mathrm{~V}$ vs SCE to avoid over-oxidising the polymer films. In this solution, the phosphate anions, $\mathrm{HPO}_{4}{ }^{2-}$ and $\mathrm{H}_{2} \mathrm{PO}_{4}{ }^{-}$, are large and will give rise to mixed ion transport, while the smaller chloride anions are easily exchanged.

The steady-state cyclic voltammograms recorded at various scan rates are shown in Fig. 7a. It is clear from these voltammograms that the PPyOx film is electroactive, which indicates that relatively small amounts of insoluble HOx have deposited at the surface. The voltammograms show evidence of cation exchange. The prominent reduction peak occurs at potentials
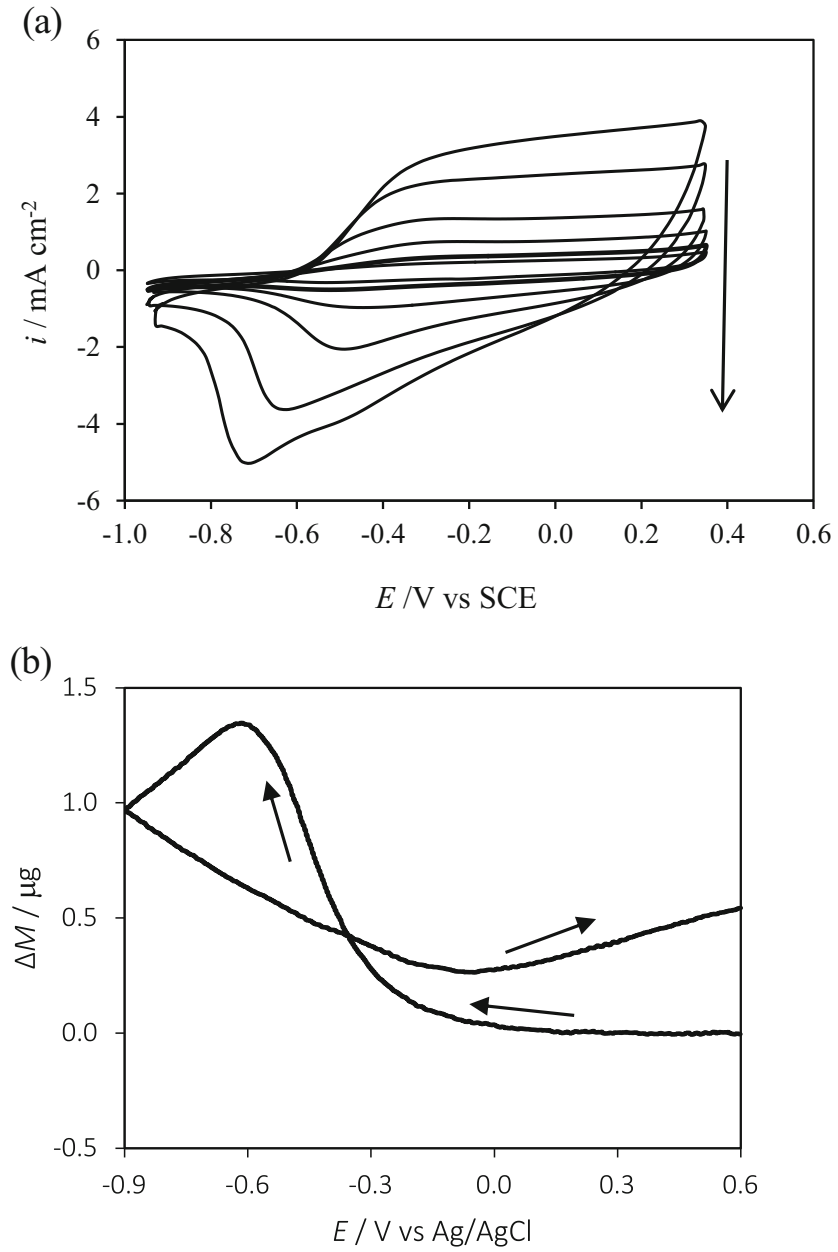

Fig. 7 a Steady-state cyclic voltammograms (10th cycle) of PPyOx recorded in PBS at scan rates of 5, 10, 25, 50, 100 and $150 \mathrm{mV} \mathrm{s}^{-1}$ in PBS. b Current (dashed line) and mass changes (solid line) plotted as a function of potential using EQCM for PPyOx (deposited to $70 \mathrm{mC} \mathrm{cm}^{-2}$ ) cycled in PBS at $2 \mathrm{mV} \mathrm{s}^{-1}$ that are in the region associated with cation transport $[21,36]$ and is associated with $\mathrm{Na}^{+}$insertion from the phosphate electrolyte. The peak potential shifts from about -0.48 to $0.65 \mathrm{~V}$ vs SCE as the scan rate is increased from 5 to $150 \mathrm{mV} \mathrm{s}^{-1}$, while the broad oxidation wave remains centred at approximately $-0.37 \mathrm{~V}$ vs SCE. No other significant peaks were observed during cycling in the PBS solution, and this indicates that cation transport is the predominant exchange process. The exchange properties of polypyrrole depend on the size, type and valence of the dopant. When small mobile dopants are employed, charge neutrality is achieved by the expulsion of the anionic dopant on reduction of the polymer. However, with large dopants, such as polystyrenesulfonate or dodecylbenzenesulfonate, the polymer behaves like a cation exchanger and cations are transferred from the solution to the polymer matrix to maintain charge balance on reduction [20-23]. This appears to be the case with the PPyOx.

These cation exchange properties were studied further using EQCM, and a typical EQCM plot is presented in Fig. $7 \mathrm{~b}$, which shows the estimated mass change recorded at a function of the applied potential for a thin polymer film. Using the Sauerbry equation (Eq. 1), the estimated mass was obtained using the frequency shift which was measured as the potential was cycled at $2 \mathrm{mV} \mathrm{s}^{-1}$ between 0.6 and $-0.9 \mathrm{~V}$ vs $\mathrm{Ag} \mid \mathrm{AgCl}$. An increase in the mass is evident on reduction of the polymer film which is consistent with the uptake of cations. This increase is observed at about $0.10 \mathrm{~V}$ vs $\mathrm{Ag} / \mathrm{AgCl}$ and continues to reach a maximum value at about $-0.6 \mathrm{~V}$ vs $\mathrm{Ag} / \mathrm{AgCl}$. On the reverse cycle, the mass slowly decreases corresponding to the release of the cations. Again, this can be attributed to the behaviour of a cation exchanger. It is also evident that the rate of the mass increase (forward cycle) is considerably higher than the rate of the mass loss (reverse cycle), indicating that the reduction process, with the incorporation of cations, is faster than the oxidation process with the expulsion of the cations. The mass increase between 0.10 and $0.60 \mathrm{~V} \mathrm{vs} \mathrm{Ag} / \mathrm{AgCl}$ on the reverse scan indicates the incorporation of anions. One possible explanation for this transition to anion uptake may be that after the large intake of $\mathrm{Na}^{+}$, some of these cations become trapped leading to a subsequent ingress of anions to maintain charge neutrality. Indeed, there is an overall mass increase by the end of the cycle showing that not all the incorporated ions during reduction are lost on oxidation.

Impedance data were recorded following a 200-min polarisation period in PBS for the PPyOx film polarised at different potentials corresponding to different degrees of oxidation. Representative plots are shown in Fig. $8 \mathrm{a}, \mathrm{b}$ where Bode plots are presented for the PPyOx at $0.10 \mathrm{~V},-0.10 \mathrm{~V}$ and $-0.60 \mathrm{~V}$ vs SCE. As evident from Fig. 7, reduction of the polymer occurs at potentials between -0.20 and about $-0.60 \mathrm{~V}$ vs SCE. The impedance recorded at $-0.60 \mathrm{~V}$ vs SCE 

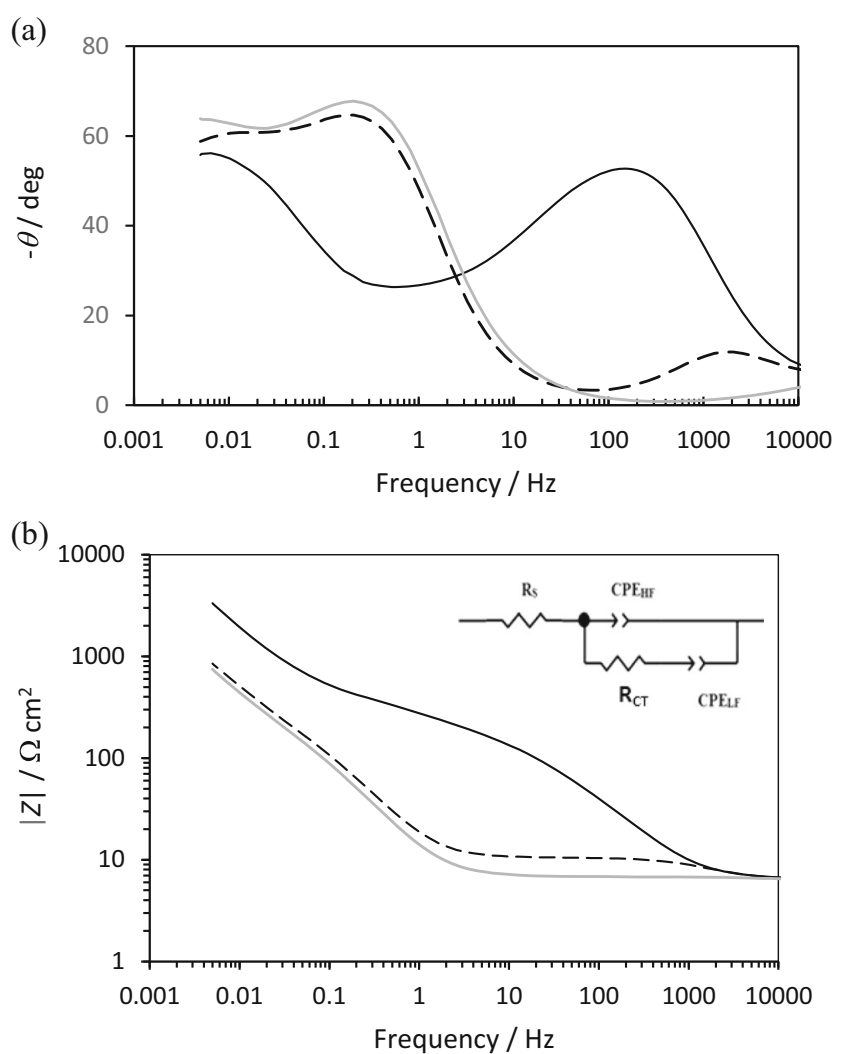

Fig. 8 a Impedance and $\mathbf{b}$ phase angle Bode plots recorded for PPyOx polarised at $0.10 \mathrm{~V}$ vs SCE (dashed line), at $0.10 \mathrm{~V}$ vs SCE (grey solid line) and at $-0.60 \mathrm{~V}$ vs SCE (black solid line)

corresponds to the reduced PPyOx. At $0.10 \mathrm{~V}$ vs SCE, the polymer is largely oxidised. The impedance data clearly illustrate that the PPyOx is conducting as relatively low impedance values are obtained in the PBS solution. The impedance data were fitted to the equivalent circuit depicted in the figure. In this circuit, Rs represents the solution resistance, $\mathrm{CPE}_{\mathrm{HF}}$ is a constant phase element, which represents the double-layer capacitance, $R_{\mathrm{CT}}$ represents the charge transfer resistance and $\mathrm{CPE}_{\mathrm{LF}}$ corresponds to the lower frequency data and gives information on the polymer capacitance and charge storage properties of the polymer [37]. Constant phase elements with a fractional exponent, $n$, give a measure of surface inhomogeneity, with $n$ adopting values between 0.0 and 1.0. The higher $n$ values, $n>$ 0.95 , point to a high degree of surface homogeneity and correspond to a capacitor, while $n$ values in the vicinity of 0.5 represent a diffusion-controlled process. The $n$ values obtained for $\mathrm{CPE}_{\mathrm{LF}}$ on fitting the data to the equivalent circuit were approximately 1.0 for applied potentials corresponding to the oxidised polymer, and as the polymer was reduced, the $n$ value approached 0.5 , with a value of 0.52 obtained at $-0.90 \mathrm{~V}$ vs
SCE. The $n$ value began to deviate from 1.0 at $0.40 \mathrm{~V}$ vs SCE, and this corresponds to the reduction of the polymer film. The emergence of a diffusional process may be related to the ingress of $\mathrm{Na}^{+}$, and its solvated water molecules as the polymer is reduced to form $\mathrm{PPy}^{\circ} n \mathrm{Ox}^{-} n \mathrm{Na}^{+} b \mathrm{H}_{2} \mathrm{O}$. The capacitance and charge transfer resistance of PPyOx are plotted as a function of the applied potential in Fig. 9, where it is evident that the capacitance is reduced on reduction of the polymer and this is accompanied by an increase in the resistance. Again these variations in the magnitude of the capacitance and resistance are seen at about -0.30 to $0.40 \mathrm{~V}$ vs SCE and can be attributed to the reduction of the PPyOx. The capacitance values of 12 to $15 \mathrm{mF} \mathrm{cm}^{-2}$ combined with the low resistance values observed when the polymer is oxidised (Fig. 9) correspond to a conducting polymer with little evidence of any precipitation of the insoluble HOx. Precipitates of HOx are insulating, and this would lead to an increase in the polymer resistance and a loss in the charging capacitance. Furthermore, the capacitance remains relatively high as the polymer is reduced with a value of about $3 \mathrm{mF} \mathrm{cm}^{-2}$ at $-0.50 \mathrm{~V}$ vs SCE. It was not possible to compute the charging capacitance at lower applied potentials as the $n$ value deviated too far from 1.0. These relatively high values are consistent with the formation of $\mathrm{PPy}^{\mathrm{o}} n \mathrm{Ox}^{-} n \mathrm{Na}^{+} b \mathrm{H}_{2} \mathrm{O}$, indicating cation exchange, which is in good agreement with the voltammetry data (Fig. 7).

It appears from the voltammetry and impedance data that the oxacillin is not released on reduction of the polymer film. These exchange properties were further studied by carrying out release studies, where the PPyOx was reduced and the concentration of $\mathrm{Ox}^{-}$was monitored. The PPyOx film was electrochemically reduced at $-0.60 \mathrm{~V}$ vs SCE, and the solution was analysed to determine the levels of $\mathrm{Ox}^{-}$exchange. This potential is more electronegative than the reduction wave seen at the lower scan rates enabling the reduction of the polymer film. The PPyOx was also polarised at a more electropositive potential of $0.30 \mathrm{~V}$ vs SCE, beyond the region where reduction occurs. The concentration of oxacillin measured as a function of time is shown in Fig. 10a at fixed potentials of $-0.60 \mathrm{~V}$ vs SCE and $0.30 \mathrm{~V}$ vs SCE. Statistically, there appears to be no difference between the amounts of oxacillin exchanged at $-0.60 \mathrm{~V}$ and $0.03 \mathrm{~V}$ vs SCE. Furthermore, relatively low amounts of oxacillin, $0.2 \mu \mathrm{g} \mathrm{cm}^{-2}$, are measured suggesting that the small quantities may arise as a result of slow diffusion of oxacillin that is trapped, but not bound as a dopant, or precipitated HOx, from the polymer matrix. The influence of the applied potential is more clearly shown in Fig. 10b. Again, it is clear 
Fig. 9 a Polymer capacitance and b charge transfer resistance, $R_{\mathrm{CT}}$, of PPyOx plotted as a function of the applied potential $(n=3)$

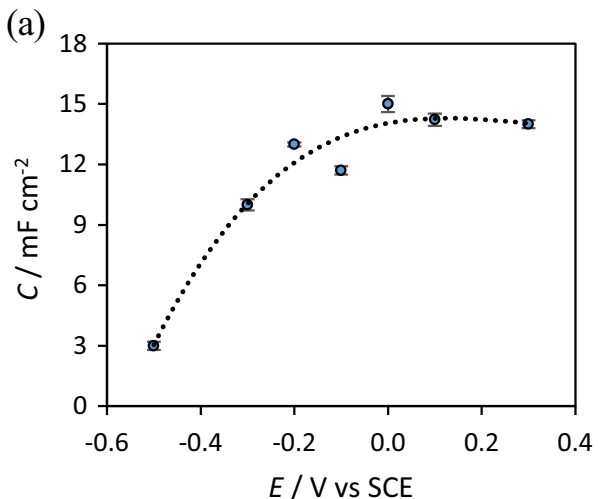

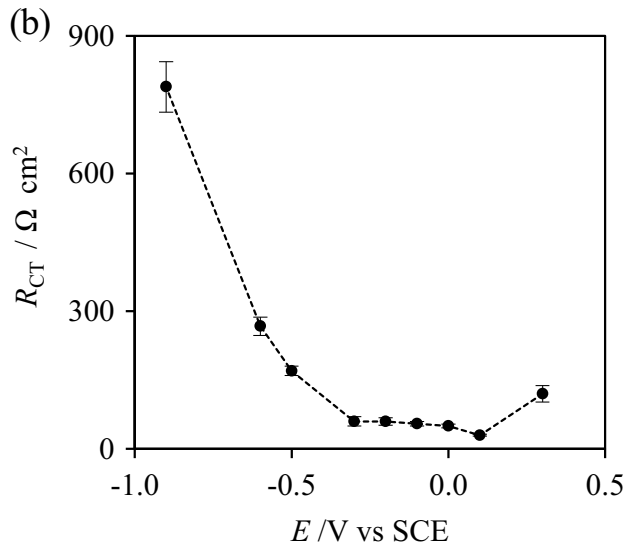

from these data that the applied potential has no influence on the amount released. Similar results were obtained for the PPyOx films formed at platinum and titanium substrates. This suggests that oxacillin is trapped as an immobile dopant. These processes are illustrated in Eqs. 6 and 7, where Eq. 6 describes the reduction of the polymer film and Eq. 7 refers to the oxidation reaction, where $\mathrm{Na}^{+}$ions are released and additional anions, $\mathrm{A}^{-}$, from the electrolyte solution may also be incorporated, consistent with the mass changes seen in Fig. $7 b$.

$$
\begin{aligned}
& \mathrm{PPy}^{n+} \cdot n \mathrm{Ox}^{-}+\mathrm{ze}^{-}+n \mathrm{Na}^{+}+b \mathrm{H}_{2} \mathrm{O} \leftrightharpoons \mathrm{PPy}^{0} \cdot n \mathrm{Ox}^{-} \\
& \cdot n \mathrm{Na}^{+} b \mathrm{H}_{2} \mathrm{O} \\
& \mathrm{PPy}^{\mathrm{o}} \cdot n \mathrm{Ox}^{-} \cdot n \mathrm{Na}^{+} \cdot b \mathrm{H}_{2} \mathrm{O} \\
& \quad+\mathrm{mA}^{-}-\mathrm{ze}^{-}-a \mathrm{Na}^{+}-x \mathrm{H}_{2} \mathrm{O} \quad \leftrightharpoons \quad \mathrm{PPy}^{(m+a)+} \cdot n \mathrm{Ox}^{-} \\
& \cdot \mathrm{mA}^{-}(n-a) \mathrm{Na}^{+}(b-x) \mathrm{H}_{2} \mathrm{O}
\end{aligned}
$$

The immobile nature of oxacillin may be connected to its large size and to the steric hindrance that is present in the structure. This makes the oxacillin a large rigid molecule with poor flexibility, which is consistent with the low doping level of 0.12 observed for the early stages of polymer formation. The primary exchange process, as shown in Fig. 7, is cation exchange, and this means that $\mathrm{Ox}^{-}$will remain largely incorporated within the polypyrrole matrix.

\section{Modification of PPyOx with chitosan}

The PPyOx was further modified with chitosan to enhance its biomedical properties. The antimicrobial and antifungal properties of chitosan are well known and are generally associated with the polycationic nature of chitosan [38]. The chitosan film was prepared by drop casting $10 \mu \mathrm{L}$ of a $0.5 \% \mathrm{w} / \mathrm{v}$ solution of chitosan on the PPyOx surface. The addition of this film had little influence on the currents recorded during cyclic voltammetry experiments as illustrated in Fig. 11a, where voltammograms recorded for PPyOx and the chitosanmodified PPyOx are compared in PBS buffer. While chitosan is generally described as being cationic due to protonation of the amino group, the $\mathrm{pKa}$ of chitosan is 6.5, and given that the PBS buffer has a $\mathrm{pH}$ of 7.4, then the chitosan will remain largely uncharged with only approximately $10 \%$ of the amino groups protonated. As a consequence, the ingress of $\mathrm{Na}^{+}$as the PPyOx is reduced should not be significantly inhibited by repulsive forces with the positively charged amino groups. However, as shown in Fig. 11a, there is a shift in the reduction peak by about $100 \mathrm{mV}$ to more electropositive
Fig. 10 a Release of oxacillin from PPyOx as a function of time at $0.30 \mathrm{~V}$ (black circle) and $0.60 \mathrm{~V}$ (white circle) vs SCE. b The influence of applied potential on the release of oxacillin from PPyOx $(n=3)$
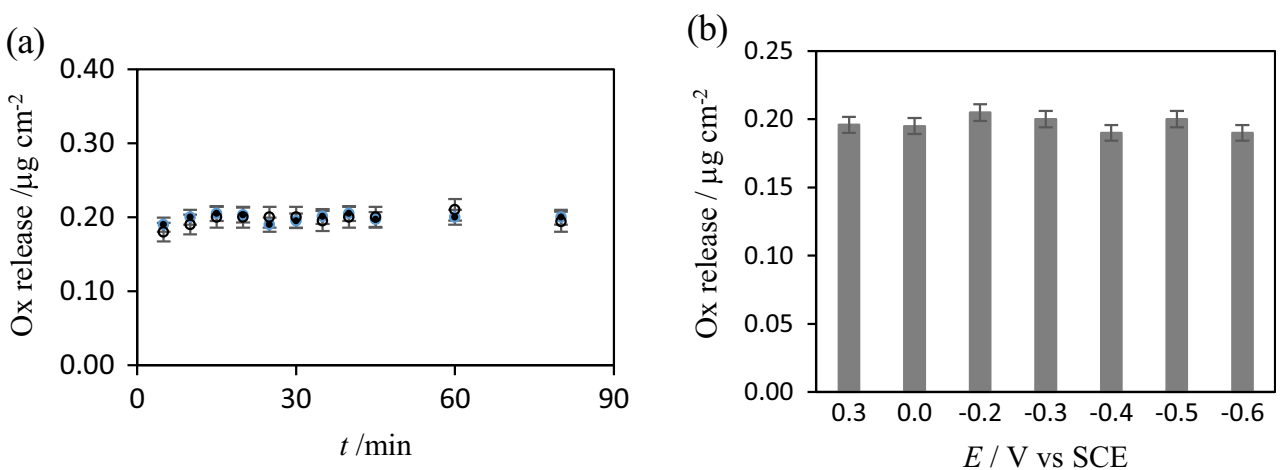
Fig. 11 a Cyclic voltammograms recorded at $5 \mathrm{mV} \mathrm{s}^{-1}$ and $\mathbf{b}$ impedance data recorded at $0.10 \mathrm{~V}$ vs SCE in PBS for PPyOx (solid line) and PPyOx modified with chitosan (dashed line)

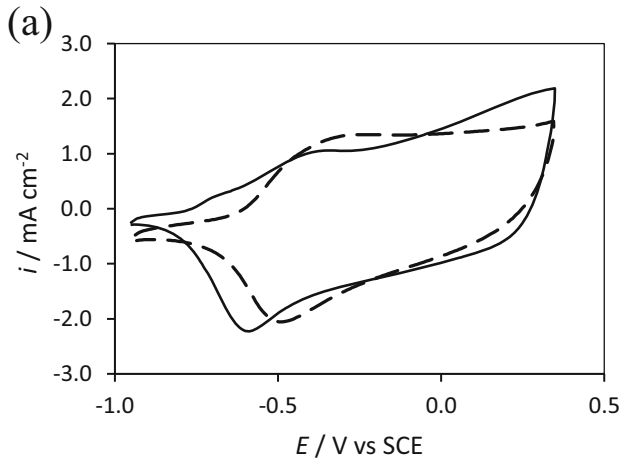

(b)

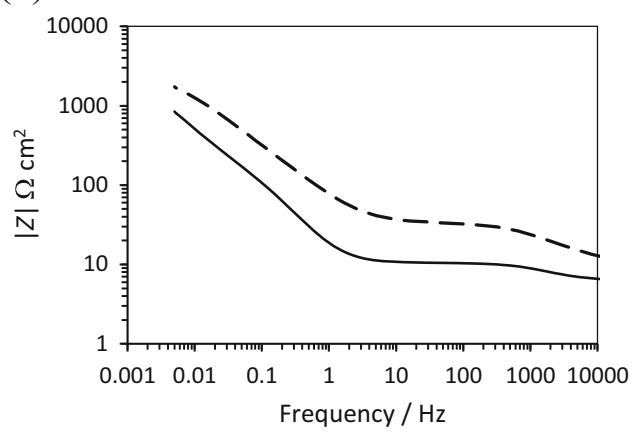

potentials with the addition of the chitosan layer, while the peak current is only slightly reduced from 2.2 to $2.0 \mathrm{~mA} \mathrm{~cm}{ }^{-2}$. This may indicate some variations in the exchange properties of the chitosan-modified PPyOx films. The more electropositive potentials indicate some anion exchange, and this may be related to Eq. 7, where the reduction of the chitosan-modified PPyOx involves both the release of $\mathrm{A}^{-}$and the ingress of $\mathrm{Na}^{+}$, while reduction of PPyOx proceeds mainly with the ingress of $\mathrm{Na}^{+}$. This transition to mixed ion exchange for the chitosan-modified PPyOx film indicates less efficient intake and release of $\mathrm{Na}^{+}$, which may be related to the insulating nature of chitosan or to the small number of protonated amino groups that exist at a $\mathrm{pH}$ of 7.4 .

The impedance response of PPyOx and chitosanmodified PPyOx is compared in Fig. 11b where it is evident that the additional chitosan layer increases somewhat the impedance of the system. The charging capacitance of the polymer was reduced from 14 to $4.9 \mathrm{mF} \mathrm{cm}^{-2}$, and a sevenfold increase in the charge transfer resistance was observed for the chitosanmodified PPyOx. However, the values obtained with the chitosan-modified PPyOx indicate a conducting system. The chitosan layer had little or no influence on the release of $\mathrm{Ox}^{-}$from the polymer matrix, and data similar to that shown in Fig. 10 were obtained, indicating that the $\mathrm{Ox}^{-}$is maintained as an immobile dopant. The presence of the chitosan did give rise to an increase in the polymer adhesion. While strongly adherent PPyOx films were formed, prolonged reduction periods at potentials of $-0.60 \mathrm{~V}$ vs SCE and lower did lead to some delamination of the polymer. This is probably connected to the ingress of large amounts of $\mathrm{Na}^{+}$cations and their solvated water molecules that result in structural damage to the polymer matrix [11]. The addition of the chitosan layer inhibited the delamination of PPyOx at these reduction potentials, and this may be related to the mixed ion exchange behaviour, where less $\mathrm{Na}^{+}$is incorporated and released from the polymer matrix. The chitosan layer reduces somewhat the conductivity of the polymer and modifies slightly the exchange properties, but its most significant effect is seen in terms of the adherent quality of the reduced PPyOx.

These results show that PPyOx and the chitosanmodified PPyOx provide a conducting surface with an immobilised antibiotic. There is considerable interest in the immobilisation of antibiotics to prevent implant infections, bacterial colonisation and biofilm formation, and porous polypyrrole films doped with large immobile antibiotics may have applications in this area [39]. Wearable electronic textiles based on polypyrrole are another research area that is receiving a lot of interest [6]. Polypyrrole with its positively charged backbone, with polarons and bipolarons that are capable of disrupting the cell wall, combined with an antibiotic that is not lost or leached from the textile may be attractive in these applications.

\section{Conclusions}

Pyrrole was electropolymerised in a solution containing oxacillin as the sodium salt and pyrrole to generate an oxacillin-doped polypyrrole film. This film was deposited at a fixed potential of $0.80 \mathrm{~V}$ to give a film thickness of $1.50 \pm 0.15 \mu \mathrm{m}$. Smooth polymer films, very different to the typical cauliflower morphology observed for polypyrrole, were obtained, and this seems to be related to the equilibrium between the $\mathrm{HOx}$ and $\mathrm{Ox}^{-}$ at the polymer solution interface and the lower solubility of HOx. The cross sections of the polymer did show a more porous structure, typical of polypyrrole. A relatively low doping level of 0.12 was observed during the initial stages of polymer formation. The oxacillin-doped polypyrrole films showed high conductivity, with a high charging capacitance and a relatively low charge transfer resistance. The $\mathrm{PPyOx}$ exhibited cation exchange properties. On reduction of the polymer film, only very low levels of oxacillin were detected, and this was attributed 
to the slow diffusion of oxacillin trapped within the porous film. Instead, due to the cation exchange properties of the oxacillin, it largely remained within the polymer matrix to give an immobilised antibiotic, and therefore it may find applications in coating implants and wearable electronic textiles.

This study highlights the important role of the pKa of the neutral undissociated molecule and the rate of electropolymerisation. By selecting dopants with $\mathrm{pKa}$ values of 2.7 and higher and by controlling the rate of electropolymerisation to minimise a reduction in the interfacial $\mathrm{pH}$, conducting polymers with little or no precipitation of the insoluble neutral molecule can be formed. This is particularly relevant to large organic molecules, such as drugs and antibiotics.

Funding information The authors would like to acknowledge funding from the Irish Research Council for Science, Engineering and Technology (IRCSET) Ireland.

\section{References}

1. Guimard NK, Gomez N, Schmidt CE (2007) Conducting polymers in biomedical engineering. Prog Polym Sci 32(8-9):876-921

2. Kopecka J, Kopecky D, Vrnata M, Fitl P, Stejskal J, Trchova M, Bober P, Moravkov Z, Prokes J, Sapurina I (2014) Polypyrrole nanotubes: mechanism of formation. RSC Adv 4(4):1551-1558

3. Nishizawa M, Nozaki H, Kaji H, Kitazume T, Kobayashi N, Ishibashi T, Abe T (2007) Electrodeposition of anchored polypyrrole film on microelectrodes and stimulation of cultured cardiac myocytes. Biomaterials 28(8):1480-1485

4. Gomez N, Schmidt CE (2007) Nerve growth factor-immobilized polypyrrole: bioactive electrically conducting polymer for enhanced neurite extension. J Biomed Mater Res 81A(1):135-149

5. George PM, Lyckman AW, LaVan DA, Hegde A, Leung Y, Avasare R, Testa C, Alexander PM, Langer R, Sur M (2005) Fabrication and biocompatibility of polypyrrole implants suitable for neural prosthetics. Biomaterials 26(17):3511-3519

6. Lima RMAP, Alcaraz-Espinoza JJ, da Silva FAG de Oliveira HP (2018) Multifunctional wearable electronic textiles using cotton fibers with polypyrrole and carbon nanotubes. Appl Mater Interfaces 10:13783-13795

7. Forero López AD, Lehr IL, Brugnoni LI, Saidman SB (2018) Improvement in the corrosion protection and bactericidal properties of AZ91D magnesium alloy coated with a microstructured polypyrrole film. J Magnesium alloys 6(1):15-22

8. Maráková N, Humpolícek P, Kaspárková V, Capáková Z, Martinková L, Bober P, Trchová M, Stejskal J (2017) Antimicrobial activity and cytotoxicity of cotton fabric coated with conducting polymers, polyaniline or polypyrrole, and with deposited silver nanoparticles. Appl Surf Sci 396:169-176

9. Ignatova $\mathrm{M}$, Labaye $\mathrm{D}$, Lenoir $\mathrm{S}$, Strivay D, Jérôme R, Jérôme C (2003) Immobilization of silver in polypyrrole/polyanion composite coatings: preparation, characterization, and antibacterial activity. Langmuir 19(21):8971-8979

10. Hendy GM, Breslin CB (2019) The incorporation and controlled release of dopamine from a sulfonated $\beta$-cyclodextrin-doped conducting polymer. J Polym Res 26(3):61
11. Ryan EM, Breslin CB (2018) Formation of polypyrrole with dexamethasone as a dopant: its cation and anion exchange properties. J Electroanal Chem 824:188-194

12. Svirskis D, Sharma M, Yu Y, Garg S (2013) Electrically switchable polypyrrole film for the tunable release of progesterone. Ther Deliv 4(3):307-313

13. Massoumi B, Entezami A (2002) Electrochemically-controlled binding and release of dexamethasone from conducting polymer bilayer films. J Bioact Compat Polym 17(1):51-62

14. Pernaut J-M, Reynolds JR (2000) Use of conducting electroactive polymers for drug delivery and sensing of bioactive molecules. A redox chemistry approach. J Phys Chem B 104(17):4080-4090

15. Leprince L, Dogimont A, Magnin D, Demoustier-Champagne S (2010) Dexamethaasone electrically controlled release from polypyrrole-coated nanostructured electrodes. J Mater Sci Mater Med 21(3):925-930

16. Carquigny S, Lakard B, Lakard S, Moutarlier V, Hihn J-Y, Viau L (2016) Investigations of pharmaceutically active ionic liquids as electrolyte for the electrosynthesis of polypyrrole and active component in controlled drug delivery. Electrochim Acta 211:950-961

17. Seyfoddin A, Chan A, Chen W-T, Rupenthal ID, Waterhouse GIN, Svirskis D (2015) Electro-responsive macroporous polypyrrole scaffolds for triggered dexamethasone delivery. Eur J Pharm Biopharm 94:419-426

18. Sirivisoot S, Pareta R, Webstar TJ (2011) Electrically-controlled drug release from nanostructured polypyrrole coated on titanium. Nanotechnology 22(8):085101

19. Wadhwa R, Lagenaure CF, Cui XT (2006) Electrochemically controlled release of dexamethasone from conducting polymer polypyrrole coated electrode. J Control Release 110(3):531-541

20. Maia G, Torresi RM, Ticianelli EA, Nart FC (1996) Charge compensation dynamics in the redox process of polypyrrole modified electrodes. J Phys Chem 100(39):15910-15916

21. Syritski V, Opik A, Forsen O (2003) Ion transport investigations of polypyrrole doped with different anions by EQCM and CER techniques. Electrochim Acta 48(10):1409-1417

22. Bruckenstein S, Chen J, Jureviciute I, Hillman AR (2009) Ion and solvent transfers accompanying redox switching of polypyrrole films immersed in divalent anion solutions. Electrochim Acta 54(13):3516-3525

23. Latonen RM, Akieh MN, Vavra K, Bobacka J, Ivaska A (2013) Ion exchange behaviour of polypyrrole doped with large anions in electrolytes containing mono- and divalent metal ions. Electroanalysis 25(4):991-1004

24. Ryan EM, Breslin CB, Moulton SE, Wallace GG (2013) The effect of dopant $\mathrm{pKa}$ and the solubililty of corresponding acid on the electropolymerisation of pyrrole. Electrochim Acta 92:276-284

25. Carja G, Kameshima Y, Ciobanu G, Chiriac H, Okada K (2009) New hybrid nanostructures based on oxacillin-hydrotalcite-like anionic clays and their textural properties. Micron 40(1):147-150

26. Yang G, Feng S, Liu H, Yin J, Zhang L, Cai L (2007) On-line clean-up and screening of oxacillin and cloxacillin in human urine and plasma with a weak ion exchange monolithic column. J Chromatogr B 854(1-2):85-90

27. Sauerbrey G (1959) The use of quartz oscillators for weighing thin layers and for microweighing. Z Phys 155(2):206-222

28. Fakhry A, Cachet J, Debiemme-Chouvy C (2015) Mechanism of formation of templateless electrogenerated polypyrrole nanostructures. Electrochim Acta 179:297-303

29. Raudsepp T, Marandi M, Tamm T, Sammelselg V, Tamm J (2008) Study of the factors determining the mobility of ions in the polypyrrole films doped with aromatic sulfonate anions. Electrochim Acta 53(11):3828-3835

30. Popescu S, Ungureanu C, Albu AM, Pirvu C (2014) Poly(dopamine) assisted deposition of adherent PPy film on Ti. Prog Org Coat 77(11):1890-1900 
31. Briseno AL, Baca A, Zhou Q, Lai R, Zhou F (2001) Quantification of dopant ions in polypyrrole films with electrochemical ICPatomic emission spectrometry and comparison to electrochemical quartz crystal microbalance studies. Anal Chim Acta 441(1):123134

32. Genies EM, Pernaut JM (1984) Spectroelectrochemical studies of the redox and kinetic behavior of polypyrrole film. Synth Met 10(2):117-129

33. Song M-K, Kim Y-T, Kim B-S, Kim J, Char K, Rhee H-W (2004) Synthesis and characterization of soluble polypyrrole doped with alkylbenzenesulfonic acids. Synth Met 141(3):315-319

34. Tsunashima K, Matsubayashi T, Ono Y, Matsumiya M (2014) Electropolymerization of pyrrole in Bis(fluorosulfonyl)amidebased ionic liquid. ECS Electrochem Lett 3(1):G1-G4

35. Viau L, Hihn JY, Lakard S, Moutarlier V, Flaud V, Lakard B (2014) Full characterization of polypyrrole thin films electrosynthesized in room temperature ionic liquids, water or acetonitrile. Electrochim Acta 137:298-310

36. Ren X, Pickup PG (1994) The origin of the discrepancy between the low frequency $\mathrm{AC}$ capacitances and voltammetric capacitances of conducting polymers. J Electroanal Chem 372(1-2):289-291
37. Ren X, Pickup PG (1997) An impedance study of electron transport and electron transfer in composite polypyrrole + polystyrenesulfonate films. J Electroanl Chem 420(1-2):251-257

38. Martínez-Camacho AP, Cortez-Rocha MO, Ezquerra-Brauer JM, Graciano-Verdugo AZ, Rodriguez-Félix F, Castillo-Ortega MM, Yépiz-Gómez MS, Plascencia-Jatomea M (2010) Chitosan composite films: thermal, structural, mechanical and antifungal properties. Carbohy Polym 82(2):305-315

39. Hickok NJ, Shapiro IM (2012) Immobilized antibiotics to prevent orthopedic implant infections. Adv Drug Deliv Rev 64(12):11651176

Publisher's note Springer Nature remains neutral with regard to jurisdictional claims in published maps and institutional affiliations. 